\title{
O JARDIM: RETORTA DE ALQUIMISTA
}

Isabel Matos Dias

(Universidade de Lisboa)

Para o Francisco

"Todo o livro é um jardim"

F. Garcia Lorca

\section{Poesia: a "planta" de um jardim}

Pretende-se explorar, com esta reflexão, a hermenêutica do jardim, tomando como fio condutor a analogia entre o jardim e o texto, com incidência, no texto poético. Esta abordagem será acompanhada da leitura de um jardim contemporâneo português: o "Parque dos Poetas"1.

Se a interpretação do jardim como texto se vislumbra plausível, já a do texto como um jardim parece abusiva e até mesmo despropositada. No entanto, texto e jardim serão aqui pensados no horizonte de uma poiética da obra. Mas qual a natureza desta obra? A de um artefacto, de uma produção aberta ou processo contínuo. Significa isto que a obra - texto ou jardim - é inacabada e inacabável, mesmo que "feita", como insinua Baudelaire, quando se refere à obra de Corot, pintor da natureza: "uma obra feita não está necessariamente acabada, e uma obra acabada pode não estar necessariamente feita." $2 \mathrm{O}$ inacabamento da obra não é uma falha, mas abertura a múltiplas possibilidades, sendo aí que se tece a leitura que "vê" o texto ou a que "lê" o jardim. Leitura que é uma forma de deambulação do olhar ou de movimento do corpo que se apropria do

1 O "Parque dos Poetas", situado em Oeiras, foi inaugurado em 2003. É da autoria do Gabinete de Arquitectura Paisagista Francisco Caldeira Cabral e Elsa Severino.

2 C. Baudelaire, "Paysages" (1845) in Oeuvres Complètes II, Paris, Gallimard, Pléiade, 1976, p. 390.

Philosophica, 32, Lisboa, 2008, pp. 69-76 
espaço, habitando-o, transformando-o, ou, noutros termos, vivificando-o. Paradoxalmente, sendo o jardim feito de elementos vivos, todavia, ele mumifica-se, tornando-se um "pedaço de espaço", desde que não seja habitado, passeado, tal como o texto se fossiliza, se ficar reduzido a um produto "feito", unidade fechada com sentido unívoco, cindido da contínua dinâmica de reescrita que é, afinal, toda a leitura.

No texto, como no jardim ou paisagem (esclareça-se que utilizamos aqui indistintamente os termos jardim e paisagem, cientes da distinção e aproximação entre os dois termos, que, aliás, não confluíram nem na semântica, nem na sua história) ${ }^{3}$, há múltiplos sentidos ou direcções a constituir. A relação que se opera entre texto ou jardim e leitor transeunte suscita diversas metamorfoses. Relativamente ao jardim é de salientar a metamorfose do espaço operada pelo leitor, metamorfose do espaço físico e objectivo em paisagem ou jardim, do espaço espacializado em espaço espacializante; metamorfose do leitor operada pelo espaço vivo e em transformação, tornando-o habitante-caminhante. Nesta reciprocidade de trajectórias tece-se a obra, espaço polissémico, polifónico, obra in statu nascendi; obra aberta, uma vez mais, porque continuamente a fazer-se e refazer-se em consonância com diferenciados ritmos naturais, culturais, sociais, individuais.

O jardim é um pólo de articulações e enredos, onde se encontram a natureza e a cultura, o natural e o artificial, a ciência e a técnica. Embora a paisagem seja uma produção cultural, ela alia-se, de forma espontânea, à natureza, perpetuando e superando o binómio natureza-cultura.

$\mathrm{Na}$ tradição ocidental, a oposição entre a espontaneidade da natureza e a artificialidade da cultura/civilização tem sido uma constante, ora privilegiando-se a natureza, ora a cultura e a história. A metáfora do livro é um índice desta oscilação. Associa-se a natureza a um livro, fazendo dela uma linguagem, interpretada numa multiplicidade de línguas e de caligrafias, analogia que prejudica por vezes a dinâmica cultural, quando o livro é considerado um depósito de erudição. É este risco que Bernardo de Claraval indirectamente denuncia quando escreve, na Carta CVI:

"Aprende-se muito mais nos bosques do que nos livros; as árvores e os rochedos ensinar-vos-ão coisas que não se ouvem em outros sítios. Vereis com os vossos olhos que se pode extrair mel das pedras e azeite dos mais duros rochedos."

$\mathrm{O}$ bosque reenvia à profusão e impulso de um mundo vegetal selvagem, envolto em enigmas, labirintos e segredos, excedendo o controlo

${ }^{3}$ Da extensa bibliografia sobre o tema destacamos: M. Collot (dir.), Les enjeux $d u$ paysage, Bruxelles, OUSIA, 1997; M. Baridon, Naissance et renaissance du paysage, Paris, Actes Sud, 2006. 
das geometrias mentais, mais consentâneas com a ideia de jardim. A fecundidade das árvores e das pedras apodera-se da audição e do olhar. De facto, auscultamos a natureza com os olhos, surpreendendo nela fenómenos complexos: há mel - alimento energético e purificador - nas pedras e azeite nos rochedos; azeite que, para além de alimento, é fonte de luz, ilumina; mel e azeite, cuja fecundidade é preservada na consistente almotolia das pedras e das rochas. Aliás, a vida orgânica das pedras fora já sublinhada por Ovídio, em As Metamorfoses, a propósito de Deucalião e Pirra, referindo a origem mineral do nosso corpo, corpo ctónico; os ossos do corpo, tal como as pedras, emergem da Terra ${ }^{4}$.

A experiência do tempo, vivida na deambulação pelo jardim ou na produção da escrita e da leitura, constitui um outro eixo de aproximação da po(i)ética do jardim e do texto.

O contacto vital com a terra e com a pedra, com o mundo orgânico tem raízes temporais. O jardim forma-se no encontro, sempre renovado, entre diferentes manifestações do orgânico e sedimentações de múltiplas temporalidades. A paisagem é um espaço transformado em tempo e memória. São estas misturas e metamorfoses que a alquimia sempre realizou, contando tanto com as forças ocultas da natureza, que o alquimista tenta desvendar, como com a virtuosidade do operador, estabelecendo a correspondência entre os cinco elementos do mundo e os cinco sentidos da organicidade humana. O jardim é então essa privilegiada retorta. Captando forças e vibrações, o paisagista-alquimista penetra na gramática da natureza e na gramática verbal, decifrando uma pela outra. Há uma recíproca interacção e continuidade entre natureza e poesia, a energia da natureza suscitando o exercício poético, as palavras condensando e revelando segredos da natureza. O laço entre a memória, a natureza e a poesia é tão natural que Sophia de Mello Breyner o reconhece, no excurso pela sua infância:

"Na minha infância [...] nem sabia que os poemas eram escritos por pessoas, mas julgava que eram consubstanciais ao universo, que eram a respiração das coisas, o nome deste mundo dito por ele próprio. Pensava também que, se conseguisse ficar completamente imóvel e muda em certos lugares mágicos do jardim, eu conseguiria ouvir um desses poemas que o próprio ar continha em si." ${ }^{5}$

Sophia reenvia-nos à palavra poética mais arcaica, a que está inscrita na atmosfera que se respira. Ela sabe bem que a Poesia excede cada um dos poetas.

${ }^{4}$ Cf. Metamorfoses I, 393-394.

5 Cf. “Arte Poética v" in Obra Poética III, Lisboa, Caminho, 1999, p. 349. 
A leitura do texto ou jardim público que elegemos, o "Parque dos Poetas", suscita desde logo diversas interrogações sobre a própria designação: não teria mais sentido falar em poesia do que em poetas? "Parque dos Poetas", porquê? Qual a prioridade: a do parque ou a dos poetas? Será este parque uma moldura exterior de enquadramento dos poetas? Será também ele voz de poeta? Constituirá este parque um texto, apelando aos textos dos poetas? Um espaço de evocação poética? O "Parque" este parque -, é um espaço polivalente e polifónico, apontado para o futuro, distanciando-se de um suposto museu de estátuas, um "clube de poetas mortos". Na sua composição e morfologia está patente o cruzamento do jardim ou paisagem com a poesia.

\section{A Árvore como matriz}

Ao entrar no "Parque dos Poetas" deparamos com o modelo matricial do seu traçado, a Árvore, e com uma disseminação alastrante de folhas: folhas de árvores, folhas de pedra, folhas de água (as fontes), folhas de aço inoxidável (a moldura dos jardins dos poetas), e, por detrás de tudo isto, a Folha da Planta do Projecto do "Parque dos Poetas".

Os Jardins dos Poetas aludem à singularidade da palavra de cada poeta. Cada jardim espelha um estilo, traduzindo-o na sua composição, vegetação e traçado de um percurso. A unidade paisagística entre estes vinte poetas do século XX reside na repetição da forma de cada jardim: uma folha em aço inoxidável, a que se acede pelo pecíolo, dando a sensação de recanto e recolhimento. Há um intimismo nestes jardins, espécie de lugar de refúgio da poesia; jardins que incitam à memória, desafiando a palavra poética que habita em cada um de nós.

A árvore e a folha têm também dimensão simbólica. ${ }^{6}$ Retenhamos o essencial. A árvore simboliza o cosmos, a natureza no seu conjunto, imbuída de temporalidade. Perpassa e une diferentes mundos: o subterrâneo e o celeste; o ctónico e o uraniano; com as suas raízes, a árvore mergulha nas profundidades da Terra, e, com a verticalidade do tronco - "eixo cósmico" ou "eixo do mundo" -, ascende às alturas do céu, tocando-lhe com a copa das folhas dos ramos. Se o tronco simboliza união, os ramos simbolizam diferenciação e as folhas (persistentes e caducas) o ciclo da vida.

Sigamos a arquitectónica do Parque pelo desenho da Árvore.

A Alameda dos Poetas corresponde ao tronco da Árvore, os Jardins dos Poetas, às folhas dos seus ramos, a Praça da Água contém e alimenta as suas raízes.

6 Cf. R. Dumas, Traité de l'arbre. Essai d'une philosophie occidentale, Paris, Actes Sud, 2002; J. Mottet, (dir), L'arbre dans le paysage, Paris, Champ Vallon, 2002. 
A unidade e as diferenças que modelam esta Árvore são percorridas por uma linha sinusoidal que atravessa e enreda todas as suas partes, evocando uma serpente ou uma liana das florestas tropicais. O serpenteamento convida a percorrer o Parque em direcções diferentes e oscilantes, fomentando mesmo, aqui e ali, movimentos giratórios, a dança do ondulado da espiral, que combina a marcha com a sua suspensão cadenciada.

Entre o tronco - a Alameda - e as curvas da sinusóide criam-se, de um lado e do outro, espaços, com a configuração de uma meia-lua, ocupados por pedras e rochas calcárias de onde jorra água pulverizada, que acentua a luz e o brilho da pedra, o contraste entre o branco e o negro do calhau rolado, simulando nevoeiros e neblinas que escondem e fazem desaparecer as formas das pedras que mesmo agora tínhamos visto.

Estes jardins de pedras e de água são para nós jardins de memória e lugares de sugestão e de mistério. As pedras remetem-nos, por um lado, para os jardins orientais, nomeadamente os japoneses, e, por outro, para ruínas e idades históricas recuadas, como a civilização megalítica. Aliás, em certos jardins, a própria disposição das pedras reenvia aos dólmens, aqui reinterpretados como janelas de enquadramento da paisagem, pontos fulcrais de passagem de luz. Pedras que, na sua disposição, são referenciais estratégicos da leitura da paisagem. Pedras brutas que, cortadas verticalmente, dão a ver o invisível da pedra, revelando veios geométricos que as aproximam dos troncos das árvores: vegetalização da pedra? De imediato associamos este espectáculo a Roger Caillois e a Yves Bonnefoy, poetas das pedras que as tornam falantes: mineralização da palavra?

A presença forte destes jardins de pedra contrasta com a Alameda dos Poetas, ladeada por alfarrobeiras, árvore mediterrânica de folha persistente. $\mathrm{O}$ chão é em pedra, calçada à portuguesa, com lajes em forma de folha de árvore, onde estão gravados fragmentos de poemas. O caminhante, interpelado pelo texto, pára para ler, saboreando o inesperado. À medida que, a medo, se pisam as pedras escritas, somos assaltados pela magia da leitura: a palavra cristalizada desprende-se e ganha vida, reencontra a liberdade da sua respiração originária. As palavras inscritas nas folhas de pedra apoderam-se da atmosfera, esvoaçando como pássaros. Cruzam-se no ar folhas de memória: folhas de árvore, de pedra, de papel. Reencontramos o gesto aleatório de folhear um livro, descobrindo o que não se procurava, acordando o que parecia adormecido e esquecido.

\section{Simetrias especulares e diálogos topográficos}

As duas portas da entrada no "Parque dos Poetas" ajustam-se num eixo comum e são iguais na sua composição, espelhando-se e reenviando-se entre si. Ambas são cingidas por uma moldura em aço inoxidável, 
com uma malha quadriculada, à qual se sobrepõe uma chapa de ferro, em forma de árvore, com ramos e folhas estilizados. Ao lado de cada uma das portas da entrada há uma outra porta, de dimensões mais reduzidas. São portas em ferro, com grades que sugerem inclinação, por detrás das quais avultam nuvens ou folhagem. O mesmo tema repete-se ao longo do gradeamento envolvente do "Parque".

O diálogo entre a malha fechada dos recortes e as aberturas entre as grades, suscita a curiosidade no caminhante mais desprevenido: apetece entrar para ver o que se passa do outro lado das grades: mas é preciso vencer o limite da porta principal. Em termos simbólicos, a porta indica acesso e passagem entre mundos, ao mesmo tempo que devolve a liberdade para entrar ou para sair: quando aberta é um convite à entrada, ao início de um percurso.

Caminhando em direcção ao "Parque", depara-se-nos uma Praça Quadrada. Avançando pelo interior do Parque, evidencia-se a presença contínua da figura do quadrado: mesas e bancos quadrados no Parque das Merendas; árvores em caldeiras quadradas; caminhos assinalados por quadrados, distribuídos de forma aparentemente aleatória ou feitos em grelha quadricular de aço, por cujas aberturas de quadrículas espreitam a relva e as ervas; janelas quadradas; uma praça quadrada.

Porquê esta atracção pela figura do quadrado? Obsessão geométrica, escaninhos da racionalidade ou presenças inconscientes da nossa cultura?

Não esqueçamos que, na tradição romana, o povoamento do território desembocava na construção de cidades e as suas casas dispunham, no interior, de um pátio quadrado. $\mathrm{O}$ quadrado é uma figura decisiva na organização arquitectónica do espaço, conferindo-lhe estabilidade. Em termos simbólicos, o número quatro traduz estabilidade e o quadrado simboliza a Terra, que tudo suporta. Não são quatro os elementos do cosmos, tal como quatro são os pontos cardeais?

A arquitectura da Praça Quadrada é um microcosmos de formas, materiais, cores e símbolos que se repetem e desdobram ao longo de todo o Parque, numa dança especular.

Na composição desta Praça Quadrada entram materiais tradicionais, como a pedra e o ferro, e materiais contemporâneos, como o aço inoxidável, que se combinam entre si, harmoniosamente, consonância reencontrada na relação entre as formas e as cores. A forma rígida do quadrado adequa-se ao desenho ondulante da pérgola em ferro, tal como o ocre dos muros de pedra lascada combina com a luminosidade do aço inoxidável, que constitui a moldura das janelas e dos muros. Por sua vez, o cinzento férreo dos bancos e da pérgola sintoniza com o rosa e o branco da calçada. Nem mesmo a solidez dos materiais de construção - pedra e aço - se cinde da fragilidade dos elementos do mundo vegetal. Estes são variados: uns, mais singelos, como as flores das verbenas, outros, mais elaborados 
como as flores dos hibiscus. Deste manto de flores sobressaem árvores mediterrânicas, como a oliveira e o cipreste, contaminadas pela simbologia da prosperidade e paz, no caso da primeira, da longevidade e imortalidade, relativamente à segunda.

O limite exterior do Parque dos Poetas está marcado por uma outra Praça: a Praça da Água, conjunto de fontes em forma de folha. O contínuo jorrar da água cria um jogo entre o som e a luz que produz um efeito estético e cumpre uma funcionalidade: diminuir o ruído do tráfego da malha rodoviária e atenuar o impacto visual dos edifícios envolventes.

Entre a Praça Quadrada e a Praça da Água giza-se um diálogo com interlocutores contrastados: terra e água, solidez e fluidez, forma e informe.

A Praça Quadrada, recinto exterior e aberto, dá acesso quer ao interior do"Parque dos Poetas", através da porta de entrada, quer à Praça da Água, através do pórtico. A porta, o pórtico e as janelas repetem-se nas suas formas e materiais na entrada oposta, assistindo-se a um exercício de geometria simétrica que provoca a especularidade.

Ao saltar para o outro lado do "Parque", a especularidade é de novo reencontrada e transfigurada, numa harmonia de opostos temporais: o Anfiteatro, também ele em forma de folha, perpetuando o modelo da tradição greco-romana; a Fonte Cibernética, ainda em forma de folha, vértice marcante da contemporaneide, abrindo horizontes de futuro. O Anfiteatro é mirante privilegiado de participação da paisagem e ainda pólo de exibição de iniciativas culturais; a Fonte Cibernética reenvia aos célebres jogos de água das fontes dos jardins históricos, mas adiciona-lhe a máquina que marca o nosso tempo, o computador, propiciando a programação dos diferentes jactos de água coloridos e da música que os acompanha. Evocação dos órgãos de água dos jardins renascentistas? Porque os jactos podem continuamente diferenciar-se, ao pisarem-se pontos estratégicos assinalados no chão, esta Fonte é interactiva, integrando o espectador no próprio espectáculo, numa combinatória entre o artificial - a técnica - e o natural e humano. A dimensão lúdica alarga-se a gestos do quotidiano, ao brincar no Parque Infantil, à partilha da refeição no Parque das Merendas, ao simples correr ou deambular, ao descanso de quem se senta na relva ou nos bancos, lendo e olhando, sonhando. Há uma coexistência de memórias e de espaços em toda esta paisagem, que se polarizam no intimismo que rodeia a Alameda dos Poeta, contrastado com os recintos sociais e com o esconderijo e mistério do Bosque da Poesia, somente passível de ser avistado, não percorrido, de uma ponte.

Delineado na confluência entre artes diversas e saberes diferentes, desde a botânica, à mineralogia, à ecologia, à simbologia, o "Parque dos Poetas" é um espaço de diálogo entre a natureza e a cultura, o espaço urbano e o espaço suburbano, a ciência e a técnica, o natural e o artificial, a natureza e a poesia. Curiosamente, a técnica adquire neste parque raízes 
de elemento natural. O cruzamento entre artes, a mistura de materiais e de formas, o facto de estarmos numa paisagem subordinada a um tema, a poesia, são marcas do jardim contemporâneo.

\section{RESUMO}

Esta reflexão visa estabelecer uma analogia entre texto e jardim, privilegiando o texto poético e procurando mostrar a textura poética do jardim. Para mostrar a sobreposição entre o "livro da natureza" e o "livro de poesia" recorreu-se a um parque público contemporâneo português dedicado à poesia: $\mathrm{o}$ Parque dos Poetas. Salientou-se, por um lado, o exercício de misturas e de interacções de elementos diversos, patentes num jardim, aproximando-o da retorta do alquimista, por outro, tentou-se fazer uma hermenêutica desse jardim, desvendando a sua estrutura subjacente - $\mathrm{a}$ árvore $\mathrm{e}$ a folha $-\mathrm{e}$ a articulação entre espaços, formas, materiais, elementos, cores.

\section{RÉSUMÉ}

Cette réfléxion a comme but d'établir l'analogie entre un texte et un jardin, en donnant le privilège au texte poétique et en mettant en évidence la texture poétique du jardin. On prend Le Parc des Poètes, un parc public contemporain portugais, comme exemplaire de la superposition entre le "livre de la nature" et le "livre de poésie". On remarque, d'une part, que le jardin est comme la cornue de l'alchimiste où se mélangent des éléments différents et des interactions réciproques, d'autre part, on essaie de faire l'herméneutique de ce jardin, en dévoilant sa structure sousjacente - l'arbre et la feuille - et l'articulation entre des espaces, des formes, des matériaux, des élements, des couleurs. 